\title{
Demonstrative Reference and Cognitive Space: A Memory Game on Mandarin-Speaking Children
}

\author{
Lu Zhao (Corresponding author) \\ Faculty of English Language and Culture, Guangdong University of Foreign Studies \\ Baiyun District, Guangzhou, China \\ E-mail: evelynzhaol@gmail.com
}

Lu Zou

Faculty of English Language and Culture, Guangdong University of Foreign Studies Baiyun District, Guangzhou, China

Received: February 2, 2021

doi:10.5296/ijl.v13i2.18371
Accepted: March 19, 2021 Published: March 28, 2021

URL: https://doi.org/10.5296/ijl.v13i2.18371

\begin{abstract}
The development of pragmatic ability is an essential topic in language acquisition, among which demonstratives are significant to reflect human's cognition of the relation between language and the environment. The purpose of this research is to investigate the acquisition of spatial demonstratives "zhe" (this) and "na" (that) of Mandarin-speaking children through experimental design (different tool use, e.g. participants pointed at the objects with their finger or a laser pen), exploring the influence of perceptual distance on children's choice of spatial demonstratives. Through comparison with adults' data, results supported the view that 5- to 6-year-old children have already developed adult-like cognitive space when it comes to the use of spatial demonstratives, which produced an effect on the use of spatial demonstratives, proving speaker's subjective involvement in choosing the proximal or distal demonstrative in the process of communication, and rendering more evidence on children's early development of pragmatic ability.
\end{abstract}

Keywords: spatial demonstratives, cognitive space, Mandarin-speaking children, language acquisition 


\section{Introduction}

\subsection{Overview}

The acquisition of mother tongue happens when children's cognitive abilities are still developing. Therefore, it is essential to understand whether and to what extent children's language development interacts with their non-linguistic cognitive development. Vocabulary is an important part of children's language ability, among which demonstratives are significant types that can reflect human's cognition of the relation between objects mentioned and themselves, indicating the development of pragmatic ability.

Imai (2003), from a cross-linguistic point of view, concludes that the spatial deixis of all languages in the world encodes space in its morphological structure at least two distances, namely proximal and distal, which, in Mandarin, are represented as "zhe" (this) and "na" (that) (Note 1). Language is generally regarded as a presentation or expression of the real world through the processing of human mind. Demonstratives, as deictic expressions, among the most frequent words in the lexicon (Leech et al., 2014; Levinson, 2018) and among the earliest utterance infants produce (Clark, 1978), can in principle be used to indicate any object, and their meaning depends on the context of utterance (Levinson, 1983; Diessel, 1999).

Spatial demonstratives like "zhe" (this) and "na" (that) in Mandarin are generally thought to be used to indicate referents accompanied with gestures within or out of certain space, with "zhe" and "zheli" (here) denoting a proximal distance, while "na" and "nali" (there) a distal one. Nevertheless, the debate on the essential factors that determines the choice of demonstratives has recently become even intense. There are currently two main views on the distance: one is the traditional view of spatial distance (Zhu, 1982; Wang, 1985), which argues that the spatial distance determines the choice of proximal and distal demonstratives; the other is the view of mental space construction (Fauconnier, 1985; Yule, 1996), maintaining that the real factor that determines the choice of spatial demonstratives is psychological distance rather than physical distance.

Lv (1985) pointed out: "The difference between proximal and distal reference is basically spatial, but also psychological." He (2000) said: "The choice of spatial demonstratives is not entirely based on the physical distance. To a large extent, it is the psychological distance in the mind of the speaker." In addition, Xu (2001) and Ding (2003) both pointed out in their articles that spatial demonstratives expressed not only specific space-time distance, but also psychological distance. Tao (1999) studied the relationship between the choice of near and far deixis and influencing factors based on actual spoken language corpus. He believed that the specific spatial distance was not the main factor to distinguish "this" and "that". In addition to spatial distance, there are other influencing factors in discourse, such as discourse mode (referring to face-to-face dialogue, intermediary dialogue, and storytelling), textuality (referring to the construction of discourse), referential fictitiousness (that is, whether the referent is realistic or unrealistic), familiarity (the speaker thinks whether the referent is new or old to the listener) and social distance (referring to the speaker's attitude towards the referent). 
Therefore, the investigation into how children use and interpret spatial demonstratives can not only render us a window to have an insight of children's pragmatic development, but also present solid evidence towards this furious discussion. Through a "Memory Game" experiment, this study aims to show when the spatial distance remains consistent, whether Mandarin-speaking children's choice of demonstratives will be influenced by the perceptual space changed through different ways of pointing. The result proved that like adults, children's choice of demonstratives would also be affected by their perception of distance, which justified Fauconnier's theory of Mental Space.

\subsection{Adult Use of Demonstratives}

Spatial demonstratives are indispensable in our daily life, as we are accustomed to using them unconsciously combined with other characteristics when we intend to refer to something near or far away, for instance, "that green bug" or "this red pen". In general, the use of spatial demonstratives is dependent on the distance between the speaker and the objects being referred, but we would definitely be aware that sometimes the physical distance alone cannot account for our choice of deixis, especially when we refer to abstract things or items that are not on the spot. The selection of many demonstratives does not conform to the principle of "the physical distance between the speaker's location"; instead, it is closely related to the speaker's mentality and emotions. This is what we call psychological distance (Huang, 2016). Several studies have been carried out to investigate the factors that influence the use of specific demonstratives.

According to these studies, the choice of spatial demonstratives embodies information about the speaker's relationship to the referents (e.g., ownership, familiarity; see Coventry et al., 2008, 2014; Rocca et al., 2019a) and the joint attention of both speakers and listeners (Peeters and Özyürek, 2016; Rocca et al., 2019b). Rocca et al. (2019b, 2020) both conducted a large-scale DCT (Demonstrative Choice Task) to probe into participants' choice of demonstratives, which turned out that demonstrative choice was influenced by multiple semantic dimensions, including spatial, bodily, and emotional features and demonstratives were used to denote not only within physical space but also in the semantic hyperspace.

Though a series of experiments of Rocca et al. seem to approach the influence of psychological distance on the choice of demonstratives, they didn't center on this aspect, instead, they focused more on considering demonstratives as a proxy to explore the processing of semantic knowledge. Coventry et al. (2008) conducted two experiments to examine the influence of tool use and interaction with objects on the choice of spatial demonstratives in both Spanish and English, the result indicated that these factors indeed played a role in participants' decision. Xu and Zhou (2011) carried out a similar test on Mandarin-speaking students, and the result is consistent with Coventry et al (2008). Concluded from their research, the choice of spatial demonstratives was not determined by the physical distance, but by the perceptual distance, which can be affected through psychological space. This kind of effect maintains its cross-language value.

\subsection{Acquisition of Demonstratives}

Since there have been multiple studies on adults' choice of spatial demonstratives, how about 
children? Do they share the same perceptual distance with adults, or does this ability develop with age? However, research on children is not as abundant as that on adults, and the core issues are mainly around the onset time and acquisition order of demonstrative pronouns, as well as their production and comprehension characteristics (Clark \& Sengul, 1978; Tanz, 1980; Wales, 1986).

According to previous studies, demonstratives denoting perceptual space like here, there, this, and that often appear by two and a half years old, when children at their early stage of oneand two-word utterances in various languages (see Clark \& Sengul 1978, for a summary). Kong \& Chen (1999) undertook a tracking research on 135 children aged from one-year-old to five-year-olds. According to their study, the onset time of first demonstrative pronoun "zhe" was at one year and six months, and "na" was at one year and nine months.

With regard to the close interrelation between pointing gestures and spatial deixis, Bates, Camaioni and Volterra (1975) reported that children first used pointing gestures around the end of the first year, while the combination with deixis emerged around the age of two (Capirci, Iverson, Pizzuto \& Volterra, 1996). Morford and Goldin-Meadow (1992) have found that children as early as 1; 6 were able to comprehend the combination of gesture and speech, which seemed to reflect the earlier development of pragmatic comprehension than production.

Whereas, most concerns on acquisition of spatial demonstratives are based on physical distance. Long (2018) achieved a relatively comprehensive investigation on children's use of "zhe" and "na", with "zhe" referring to objects closer in physical space and "na" farther. No significant difference was found among various age groups from three to six. Webb and Abrahamson (1975) investigated from the perspective of egocentrism whether children could make a polite orientation shift and comprehend "this" and "that" from the speaker's point of view on the foundation of physical distance. Similar research was conducted by Clark and Sengul (1977) as well, inquiring into children's understanding of spatial demonstratives, namely "this, that, here, there" from the perspective of physical distance, which found that children's understanding of these two pairs of demonstratives developed with age. There were phase differences in growth, from incomprehension of the opposition between the two sets of demonstratives to the partial opposition and finally the complete opposition. This change was mainly affected by egocentrism and distance. It can also be seen from this research that when a child produces space deixis, it does not mean that he has fully mastered the usage of space deixis. Zhu et al. (1986) analyzed this egocentric phenomenon in Mandarin-speaking children, the result of which, differing from Clark et al. (1977), showed that it was formidable for children to acquire the pragmatic usage of spatial demonstratives in accord with various context before seven years old.

To recap there are certain limitations on research concerning acquisition of spatial demonstratives. First, from a cross-language perspective, the number of studies about children's use of demonstratives is considerably less than that of adults, with a great majority of them focusing on the onset time of production or the combination of pointing and deixis. For another, though plenty of research on adults has demonstrated that besides physical space there are other factors that can play a role or even have a greater difference in the choice of 
deixis, little emphasis has been laid on psychological factors. Küntay and Özyurek (2006) investigated the pragmatic development of children by examining how demonstratives were used in Turkish through interviews, a three-way demonstrative system. They reported that demonstratives relevant to distance was learned much earlier, while the special demonstrative regarding listener's attention on the objects being referred was acquired later and showed significant difference between children and adults. It is this special demonstrative that renders us more insight into the pragmatic development of children, while this aspect lacks further research. In addition, concentrating on the specific language of Mandarin, the attention put on children's acquisition is even less, leaving much space for future research to delve into the relation between children's pragmatic development and cognition.

\subsection{The Present Study}

In this study, we investigated children's interpretation of spatial demonstratives based on Fauconnier's (1985) mental space theory. Through changing the tools of pointing (finger or a laser pen), participants' physical distance with the object they refer to is kept fixed, while different tools used may change the psychological distance they perceive with objects.

Similar experiment has been conducted by Coventry et al. (2008) on English- and Spanish-speaking adults with participants pointing at the object with either their hand or a stick. The results, showing that the choice of deixis across two languages was affected by both tool use and interaction with objects, supported the view that spatial demonstrative use corresponded with a basic distinction between near and far perceptual space. Therefore, it is the perceptual space instead of purely physical space that determines the use of demonstratives. Then what variables can influence the perceptual space and how? Does this perceptual space exist in children's mind when they are able to produce spatial demonstratives in daily life? This is what this research intends to figure out.

This paper puts forward three research questions: 1) what is the performance of children and adults as a whole on the choice of spatial demonstratives; 2) will children's choice of demonstratives be affected by different tool use; 3 ) if there is an influence exerted by tool use on children's choice of demonstratives, is there any difference between the influence on adults and children?

\section{Method}

\subsection{Participants}

Participants were 30 native Mandarin speakers ( 8 male), with an average age of 23.2, who were students at Guangdong University of Foreign Studies, and 30 preschool children aged from 5 to 6 (14 male), with a mean age of 5;8. The data were collected in a kindergarten for children in Shaoyang and on college campus for adults in Guangzhou, China. All participants are right-handed and have no vision or hearing problems, language disabilities or mental disorders. They all received gifts for participation.

\subsection{Procedure}

This study adopted the "memory game" (see Coventry et al., 2008, 2014) method to conduct induced output experiments. Participants were seated at a table $(70 \mathrm{~cm}$ wide and $170 \mathrm{~cm}$ long) 
on which five colored dots (each in a different color) (Note 2) were placed at $30 \mathrm{~cm}$ intervals down the mid-line directly in front of participants (see Fig. 1), with advance confirmation that only the first two dots were within the participant's reach. The experimenter was accompanied with a puppet. Before the experiment, it was explained to the participants that this puppet would participate in the game with them. Young as the puppet, it's always difficult for it to remember which animal was placed at which point, and that's why participants were invited to point at the position and tell the puppet where the animal was put at the same time. In addition, it should be noted that the puppet also cannot understand the color alone, nor did it understand mathematics, so please do not use the description such as "the red dot", "the first row", "the first red dot" etc. The existence of a puppet can release children's anxiety of being tested and provided a more sensible reason for introducing all the requirements. After the introduction, most participants chose to use the demonstrative pronouns "zhe" and "na" directly or combine them with color, for example, "zhege hongse de dian" (on this red dot), or "nage lanse de dian" (on that blue one). Clark (1978) postulated that four stages could be identified in the process of children's acquisition of deictic expressions, namely gestures, pronominal with gestures, adnominal with gestures and the combination of pronominal and adnominal without gestures. In this experiment, as we only took the distinction of proximal and distal deixis into consideration, participants can use pronominal or adnominal with gestures randomly. For instance, they can respond with "zhege hongse de dian" (this red dot) or "nali" (there).

Considering the involvement of animals, the experimenter would first examine the common sense of children to make sure that they were familiar with every animal being used. When the experiment officially started, six animal toys were placed on six dots on the tablecloth respectively in every round, and participants had five seconds of memory time. Then all the toys would be removed, and the experimenter would ask the participant where a specific toy was put, for instance, "please show the puppet where the pig was put". Participants would give answers like, "the pig was on this red dot" or "the cow on that blue dot", pointing with their finger or a laser pen. When their answer was uttered, the exact animal toy would be put back to the position that the participant chose so as to avoid misunderstanding between experimenter and participant. The correct rate of participants' answers was not recorded, as this experiment only examined the differences between the participants' choices of spatial demonstratives "zhe" and "na". Throughout the experiment, the experimenter, the participant, and the puppet were on the same side to prevent the phenomenon of perspective shifts.

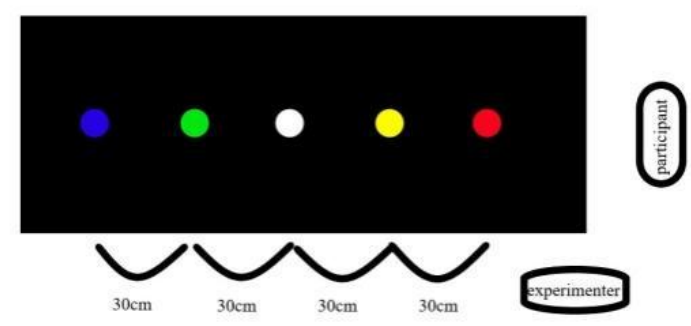

Figure 1. The schematic picture of the tablecloth with 5 colorful dots where animal toys were put on 
A total of six rounds were performed in the experiment, three rounds with finger pointing, and three rounds with a laser pen, in case the participants' choice was random. Half of the adults and children were randomly selected to start first with their finger and half first with a laser pointer. During the whole process, every utterance of deixis along with the pointing gesture either by finger or with a laser pen was guaranteed. A total of 30 responses of each participant were noted on the answer sheet file.

To encapsulate, the design used was a 5 (Distance: 5 dots on the cloth) * 2 (Tool use: finger or laser pen) *2 (Participants: adults and children) mixed design with repeated measures on the first two variables.

\section{Results}

A 5 (Distance) * 2 (Tool use) * 2 (Adults \& children) mixed design was analyzed through SPSS 17. Unlike studies (Caldano et al, 2019; Coventry, 2008; Xu, 2011) that counted on the frequency or percentage of demonstratives by performing ANOVA, this study first coded all the use of demonstratives of 60 participants into two numbers, "zhe" as 1, "na" as " 2 " (see Appendix for raw data), and then resorted to Cochran and McNemar belonging to non-parametric tests. By doing so, combing with repeated examination, a more specific reflection of participants' choice with sufficient attention being paid to individual choices was ensured, avoiding overgeneralization.

First, Cochran test was performed on the merge data of adults and children, which turned out that there was a significant effect of distance on participants' use of demonstratives, no matter pointing by finger or with a laser pen. Since there were three rounds of responses, they were analyzed respectively (by finger: Round 1: $\mathrm{N}=60, \mathrm{Q}=186.75, \mathrm{p}<0.001$; Round 2: $\mathrm{N}=60$, $\mathrm{Q}=177.848, \mathrm{p}<0.001$; Round 3: $\mathrm{N}=60, \mathrm{Q}=195.213$, $\mathrm{p}<0.001$; with a laser pen: Round 1: $\mathrm{N}=60$, $\mathrm{Q}=77.001, \mathrm{p}<0.001$; Round 2: $\mathrm{N}=60, \mathrm{Q}=74.205, \mathrm{p}<0.001$; Round 3: $\mathrm{N}=60, \mathrm{Q}=83.488$, $\mathrm{p}<0.001)$.

Cochran test only rendered us a general effect of distance on participants' choice without further demonstration. Therefore, McNemar was performed to display the accurate effect between tools used and distance. For both adults and children, there was a main interaction effect of distance and tool used (see Table 1 and Table 2). The frequency of "zhe" and "na" was shown on Table 1, from which it was vivid that there was an overwhelming preference on "zhe" the proximal deixis on the first two dots either with finger or laser pen, nevertheless, choices were divided on the middle dot and the effect of tool started to appear, with dominance of "na" by finger but remaining insistence on "zhe" by laser pen. This phenomenon lasted for the farthest two dots. Apparently, the controlling force of laser pen was more powerful than the finger pointing. The result concluded from the table of frequency coincided with the McNemar (see Table 2). Since responses on the first dot were one-hundred-percent "zhe" for both adults and children, they were not included in McNemar test, and it was from the third dot that the significant main effect $(p<0.05)$ started to emerge, which manifested the influence of distance and interaction effect, not only on the general data of adults and children as a whole, but also on adults and children respectively. 
Table 1. The total frequency of "zhe" and "na" demonstratives by distance tool use and three rounds

\begin{tabular}{|c|c|c|c|c|c|c|c|c|c|c|c|c|c|c|c|}
\hline Tool & \multicolumn{15}{|c|}{ Finger } \\
\hline Distance & 1 & & & 2 & & & 3 & & & 4 & & & 5 & & \\
\hline Round & 1 & 2 & 3 & 1 & 2 & 3 & 1 & 2 & 3 & 1 & 2 & 3 & 1 & 2 & 3 \\
\hline Zhe & 60 & 60 & 60 & 58 & 55 & 60 & 24 & 28 & 23 & 3 & 2 & 3 & 1 & 3 & 0 \\
\hline $\mathrm{Na}$ & 0 & 0 & 0 & 2 & 5 & 0 & 36 & 32 & 37 & 57 & 58 & 57 & 59 & 57 & 60 \\
\hline Tool & \multicolumn{15}{|c|}{ Laser Pen } \\
\hline Distance & 1 & & & 2 & & & 3 & & & 4 & & & 5 & & \\
\hline Round & 1 & 2 & 3 & 1 & 2 & 3 & 1 & 2 & 3 & 1 & 2 & 3 & 1 & 2 & 3 \\
\hline Zhe & 60 & 60 & 60 & 56 & 57 & 55 & 50 & 52 & 50 & 36 & 41 & 38 & 29 & 31 & 27 \\
\hline $\mathrm{Na}$ & 0 & 0 & 0 & 4 & 3 & 5 & 10 & 8 & 10 & 24 & 19 & 22 & 31 & 29 & 33 \\
\hline
\end{tabular}

Note. Distances are coded from closest 1 to farthest 5 from participants.

Table 2. Results of McNemar on Children, adults and the merging data of children and adults

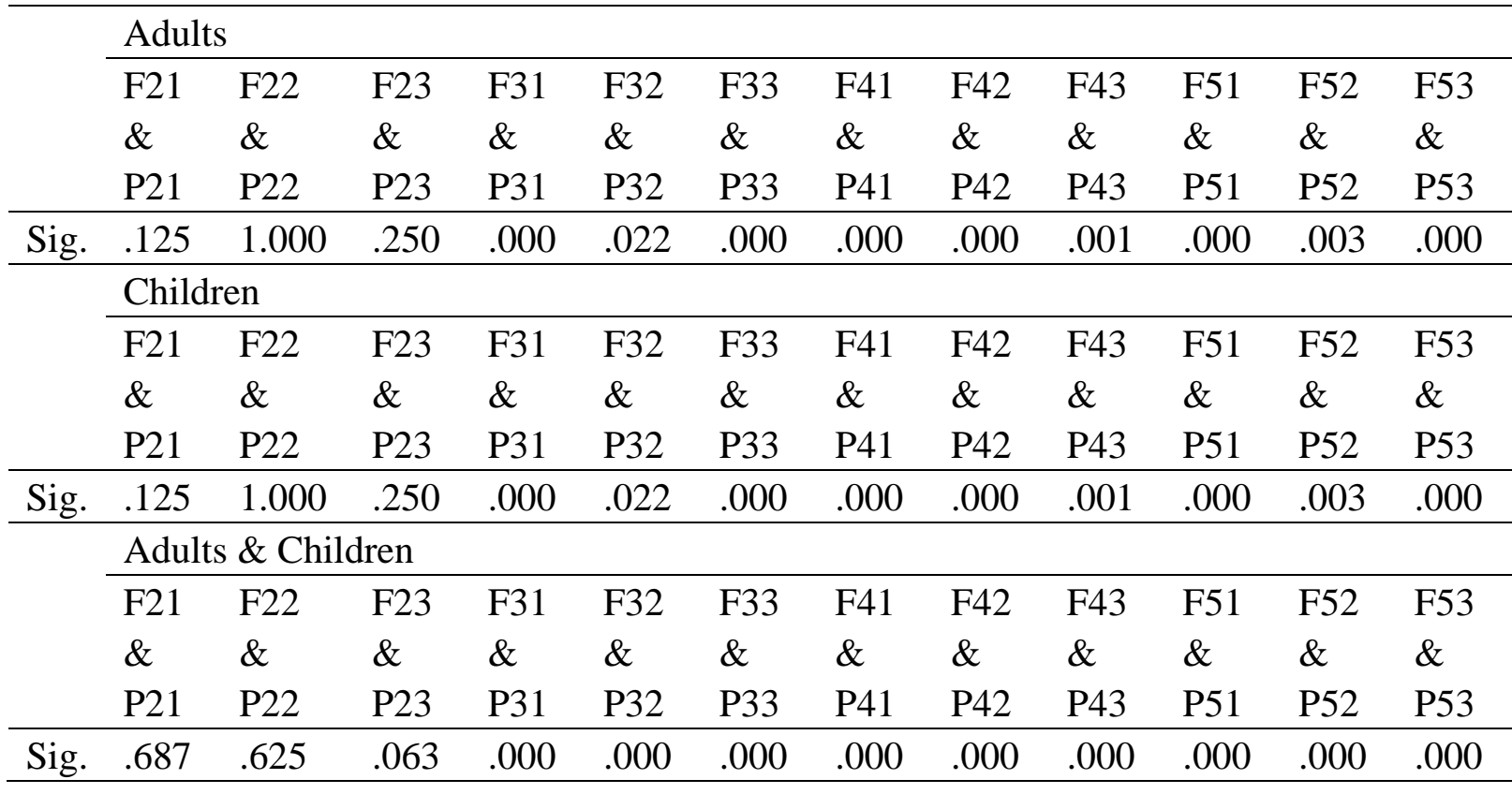

Note. The first "F" means finger, while "P" laser pen. The number following F and P stood for dots in different distance, while the last number was on behalf of rounds (e.g. "F21" means the second dot in the first round with finger pointing).

Furthermore, considering there were three rounds of response, we adopted the answer that agreed in two of the three rounds as the final answer. Because of complete consistency between adults and children on the first dots by finger and laser pen and on the fifth dots by finger, data of them were not calculated in the McNemar test (see Table 3). 
Table 3. McNemar test on responses drawn

\begin{tabular}{llllllll}
\hline & AF2 & AF3 & AF4 & AP2 & AP3 & AP4 & AP5 \\
& $\&$ & $\&$ & $\&$ & $\&$ & $\&$ & $\&$ & $\&$ \\
& CF2 & CF3 & CF4 & CP2 & CP3 & CP4 & CP5 \\
\hline $\mathrm{N}$ & 30 & 30 & 30 & 30 & 30 & 30 & 30 \\
\hline Sig. & 1.000 & .167 & 1.000 & .500 & 1.000 & .143 & 1.000 \\
\hline
\end{tabular}

Note. The first "A" means adults, while " $\mathrm{C}$ " children. The second $\mathrm{F}$ and $\mathrm{P}$ stood for finger and laser pen, as has been noted in Table 2, while the last number was on behalf of distance (e.g. "AF2" means adults' choice on the second dot when pointing by finger).

From Table 3, it was evident that there was no difference between children and adults $(p>0.05)$ when it comes to choices of spatial demonstratives with different tool use. The results of Table 3 coincided with results of general linear model, with group being used as a between-subjects factor, and distance and tools use as within-subjects factors, as we converted the data into percentages (with Greenhouse-Geisser corrections where necessary). There was no significant main effect between adults and children, $F(1,58)=1.66, p>0.05$. However, for the two within-subjects factors, there was significant main effect. As for tools use, Greenhouse-Geisser adjusted $\mathrm{F}(1,58)=157.82, \mathrm{p}<0.001$, whereas, in terms of distance, Greenhouse-Geisser adjusted $\mathrm{F}(2.89,167.43)=279.31, \mathrm{p}<0.001$. In addition, there was a significant distance * tool use interaction effect, Greenhouse-Geisser adjusted F $(2.40,139.07)$ $=55.20, \mathrm{p}<0.001$. Follow-up analyses were performed using LSD tests. "Zhe" was used more on the first two dots, and opinions began to split from the third dots $(\mathrm{p}<0.001)$. Therefore, the use of spatial demonstrative "zhe" was influenced by the distance between the speaker and the object being referred to and the psychological extending reach achieved by the tool use (see Fig. 1). Finally, as no main effect of group has been found, neither has any related significant interaction effect been found.
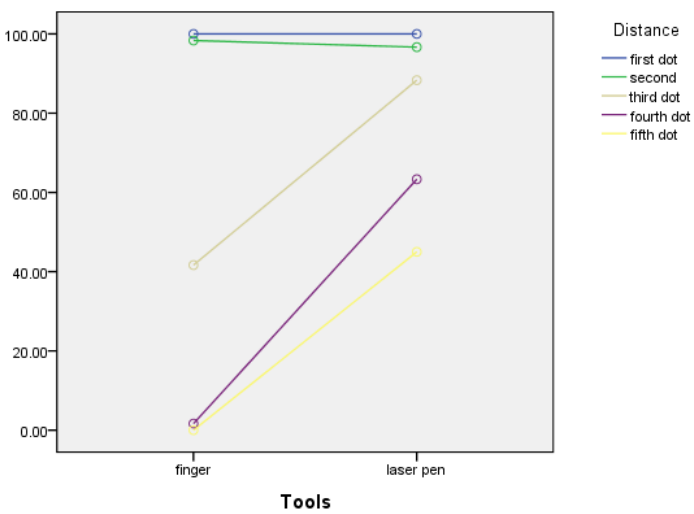

Figure 2. The general influence of tools and distance on the percentage of use of "zhe"

\section{General Discussion}

Considering that our goals are threefold, the discussion will be conducted based on the three research questions that have been specified before. First, the results have manifested that Mandarin-speaking adults' and children's choice of demonstratives are affected by distance 
and tools being used, which is consistent with Xu \& Zhou (2011) who explored the choices of Mandarin-speaking adults, meanwhile, these results also share cross-language universality with Coventry et al. (2008), whose investigation was conducted on English and Spanish adults.

The influence of distance on choice of spatial demonstratives is a common sense, as people are accustomed to associating the meaning of "far/near" that they are incorporated into directly with spatial distance. The choice of proximal or distal demonstratives is assumed to be mainly dependent on the specific spatial distance: proximal deixis is used to refer to people or objects that are near, whereas distal one is used to refer to objects in a relative distance (e.g. Lyons, 1977; Levinson, 1983). This kind of contrast is reflected in the data between choices of demonstratives on the farthest three dots and nearest two dots, despite tools.

However, the use of laser pen did not make any difference on spatial distance while it induced more proximal demonstrative "zhe" compared with same distance referred to by finger. Furthermore, many instances in daily life have revealed that the relationship between demonstratives and objects referred to is not as easy as it appears to be. According to Cognitive Linguistics (e.g. Lakoff \& Johnson, 1999), the connection between language and reality is mediated by people with cognitive ability. Cognitive semantics proposes three kinds of spaces, namely, physical space, linguistic space and cognitive space. Cognitive space is the intermediary between the linguistic form and the objective world. Since cognitive space is abstracted by people, it cannot be seen or touched. To understand it, we must use linguistic space and physical space. Physical space is the form of space in the objective world, which exists objectively and is independent from subjective will, while cognitive space is the result of people's perception of physical space. Quirk et al. (1985) maintains that the measurement of spatial proximity can be a matter of psychological rather than real distance. They further argue that the measurement of spatial distance can be extended to an even more abstract and subjective level of interpretation.

From this perspective, participants' responses can be explained. Language reflects how humans perceive and experience the world rather than a direct exhibition of the objective world. Therefore, the meaning of "far/near" does not correspond to the spatial distance, instead, it is an abstract cognition in human mind. In brief, the use of demonstratives does not depend on the actual spatial distance, but human's judgment and perception of this distance. Evidence also can be found in Caldano and Coventry (2019), which investigated the combination of location and handedness. They contended that spatial demonstratives were generated from a basic perceptual distinction between near space and far space (Longo \& Lourenco, 2006). In addition, Rocca and Walletin (2020), which conducted a large-scale Demonstrative Choice Task experiment, found out that semantic factors such as loudness, motion, manipulation can be influential. They put forward that there was a semantic hyperspace between speakers and objects. Lakoff (1987) and Marmaridou (2000) both discussed the idealized cognitive model of deixis (ICM of deixis), which they believed can construct a cognitive space. 


\section{Macrothink}

International Journal of Linguistics

ISSN 1948-5425

2021, Vol. 13, No. 2

In a word, this study does manifest that the choice of demonstratives is not determined by the physical space between speakers and objects, but dependent on interactors' perception of the distance between them and objects referred to. As has been supported by many studies as well, this is a cross-language phenomenon among adults. Then what about children? Have they developed this ideal cognitive model as early as 5- to 6-year-old, or does this model develops with age?

Taking the second and third research questions together into consideration, results have revealed no significant difference of the choices between adults and children in this study, to the effect that those children as early as five years old have already developed a cognitive space to facilitate their expression. There is no significance on the first two dots no matter what tools children employed, for the occurrences of "zhe" occupied the mainstream. However, opinions began to split from the third dot (see Table 2). To be more specific, children produced less "zhe" and more "na" when pointing by finger, while producing more "zhe" and less "na" when pointing by laser pen (see Table 1). As presented, it indicated that the two modes of pointing, namely, by finger and by laser pen, did have different extents of controlling force on the experiment. The data of children was highly similar with adults (shown in Fig. 2 and Fig. 3).
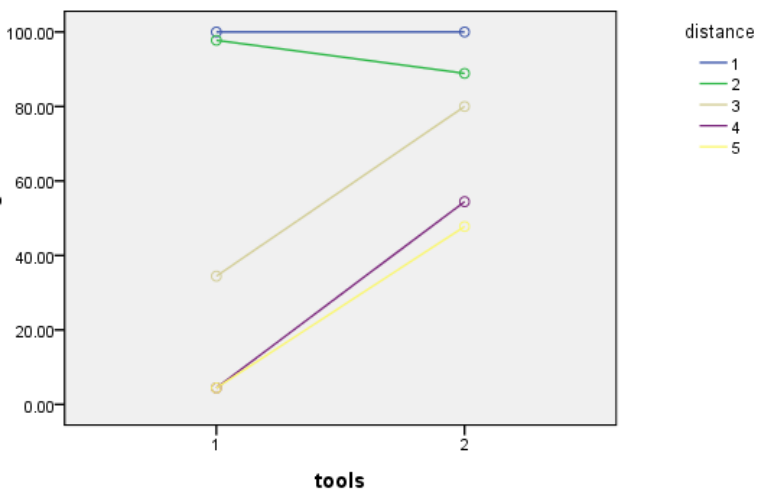

Figure 3. The percentage of children's choices with "zhe". ("finger" was coded into "1", and "laser pen" into " 2 "; tool " 1 " is by finger, " 2 " by laser pen)
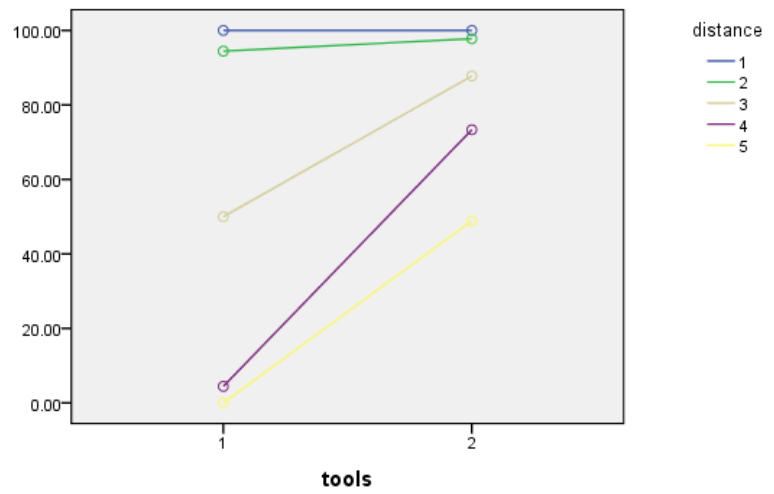

Figure 4. The percentage of adult's choices with "zhe". ("finger" was coded into " 1 ", and "laser pen" into " 2 "; tool " 1 " is by finger, " 2 " by laser pen) 


\section{Mll Macrothink}

International Journal of Linguistics

ISSN 1948-5425

2021, Vol. 13, No. 2

From figures above, it is explicit that there is no significant difference between adults and children, when it comes to the influence of tools and distance on choices of demonstratives. Though no significant difference is displayed, little discrepancy can be captured from figures above, as adults respond with relatively more "zhe" in the fourth dot with laser pen than children. Studies (such as Halligan \& Marshall, 1991; Cowey et al., 1994, 1999) have shown that the human brain can use different nervous systems to represent objects in near and far space. The near space is approximately equivalent to the range within one arm of the human body, while the far space is the range outside the arm (Kemmerer, 1999), which accords with our experimental results, as this study always kept the nearest two dots within participants' reach. Therefore, it is reasonable to deduce that the stretch length can greatly influence participants' cognitive space. Adults with longer stretch length will develop a more powerful controlling force than children, when using a laser pen. Of course, the understanding and manipulation of laser pen can be a factor that poses obstacle to children.

In conclusion, Children from five to six years old, as this study reports, have already developed adult-like cognitive space, which produces an effect on the use of spatial demonstratives, proving speaker's subjective involvement in choosing the proximal or distal demonstrative in the process of communication. Nevertheless, without comparison among children with different ages, no conclusion can be drawn whether this cognitive space is developed with language acquisition or is instinctive. Future attention need to be paid on this direction, delving into the developing process, revealing a more comprehension picture of acquisition of deixis.

\section{Acknowledgements}

This work is supported by Graduate Student Research Innovation Program of Guangdong University of Foreign Studies (Grant No. 20GWCXXM-03 awarded to Lu Zhao and her partners). Many thanks to Prof. Wu at Faculty of English Language and Culture, Guangdong University of Foreign Studies for helpful discussion at every stage of the project. We also thank Lanshan Dinuo Huaxia Kindergarten in Shaoyang, China, for assistance with participant recruitment and testing facilities. We sincerely thank the anonymous reviewers for their valuable revision comments.

\section{References}

Bates, E., Camaioni, L., \& Volterra, V. (1975). The acquisition of performatives prior to speech. Merrill-Palmer Quarterly, 21(3), 205-226.

Caldano, M., \& Coventry, K. R. (2019). Spatial demonstratives and perceptual space: To reach or not to reach?. Cognition, 191, 103989. https://doi.org/10.1016/j.cognition.2019.06.001

Capirci, O., Iverson, J., Pizzuto, E., \& Volterra, V. (1996). Gestures and words during the transition to two-word speech. Journal of Child Language, 23(3), 645-673. https://doi.org/10.1017/S0305000900008989

Clark, E. V. (1978). From gesture to word: On the natural history of deixis in language 
acquisition. Oxford: Oxford University Press.

Clark, E. V., \& Sengul, C. J. (1978). Strategies in the acquistion of deixis. Journal of Child Language, 5(3), 457-475. https://doi.org/10.1017/S0305000900002099

Coventry, K. R., Griffiths, D., \& Hamilton, C. J. (2014). Spatial demonstratives and perceptual space: describing and remembering object location. Cogn. Psychol., 69, 46-70. https://doi.org/10.1016/j.cogpsych.2013.12.001

Coventry, K. R., Valdés, B., Castillo, A., \& Guijarro-Fuentes, P. (2008). Language within your reach: near-far perceptual space and spatial demonstratives. Cognition, 108, 889-895. https://doi.org/10.1016/j.cognition.2008.06.010

Cowey, A., Small, M., \& Ellis, S. (1994). Visuospatial neglect can be worse in far than in near space. Neuropsychologia, 32, 1059-1066. https://doi.org/10.1016/0028-3932(94)90152-x

Diessel, H. (1999). Demonstratives: form, function and grammaticalization. Amsterdam: John Benjamins Publishing. https://doi.org/10.1075/tsl.42

Diessel, H. (2006). Demonstratives, joint attention, and the emergence of grammar. Cognitive Linguistics, 17, 463-489. https://doi.org/10.1515/COG.2006.015

Diessel, H. (2013). Where does language come from? Some reflections on the role of deictic gesture and demonstratives in the evolution of language. Lang. Cogn., 5, 239-249. https://doi.org/10.1515/langcog-2013-0017

Diessel, H. (2014). Demonstratives, frames of reference, and semantic universals of space. Language and Linguistics Compass, 8(3), 116-132. https://doi.org/10.1111/lnc3.12066

Ding, Q. Z. (2003). The grammatical distribution of "zhe" and "na" in modern Chinese. Chinese Teaching in the World, 2, 27-38.

Fauconnier, G. (1985). Mental spaces: aspects of meaning construction in natural language. Cambridge, Mass.: MIT Press.

Halligan, P. W., \& Marshall, J. C. (1991). Left neglect for near but not far space in man. Nature, 350, 498-500. https://doi.org/10.1038/350498a0

He, Z. X. (2000). A new introduction to pragmatics. Shanghai: Shanghai Foreign Language Education Press.

Huang, M. (2016). Spatial demonstratives and mapping phenomena under mental space theory. Cross-Linguistic \& Cross-Cultural Studies, 1, 20-26.

Imai, S. (2003). Spatial Deixis. Unpublished doctoral dissertation. The State University of New York at Buffalo.

Johnson, M. (1987). The body in the mind: The bodily basis of meaning, reason, and imagination. Chicago, IL: University of Chicago Press. https://doi.org/10.7208/chicago/9780226177847.001.0001 
Kemmerer, D. (1999). "Near" and "far" in language and perception. Cognition, 73, 35-63. https://doi.org/10.1016/S0010-0277(99)00040-2

Kenny, R. C., Debra, G., \& Colin, J. H. (2014). Spatial demonstratives and perceptual space: Describing and remembering object location. Cognitive Psychology, 69, 46-70. https://doi.org/10.1016/j.cogpsych.2013.12.001

Kong, L. D., \& Chen, C. F. (1999). The order of pronoun development in language acquisition and its theoretical explanation. Applied Linguistics, 2, 41-46.

Küntay, A. C., \& Özyurek, A. (2006). Learning to use demonstratives in conversation: what do language specific strategies in Turkish reveal?. Journal Child Lang, 33(2), 303-320. https://doi.org/10.1017/s0305000906007380

Lakoff, G. (1987). Women, fire, and dangerous things: What categories reveal about the mind. Chicago: University of Chicago Press. https://doi.org/10.7208/chicago/9780226471013.001.0001

Lakoff, G., \& Johnson, M. (1999). Philosophy in the Flesh: The embodied mind and its challenge to western thought. New York: Basic Books.

Leech, G., Rayson, P., \& Wilson, A. (2014). Word frequencies in written and spoken English: based on the British national corpus. London: Routledge. https://doi.org/10.4324/9781315840161

Levinson, S. C. (1983). Pragmatics. Cambridge: Cambridge University Press. https://doi.org/10.1017/CBO9780511813313

Levinson, S. C. (2018). Introduction: demonstratives: patterns in diversity. In M. J. Dunn, N. J. Enfield, S. Cutfield, S. C. Levinson, \& S. Meira (Eds.), Demonstratives in cross-linguistic perspective (pp. 1-42). Cambridge: Cambridge University Press. https://doi.org/10.1017/9781108333818.002

Long, J. Y. (2018). The acquisition of demonstrative pronouns by Mandarin-speaking children. Master's Thesis, Hunan University. Retrieved from http://www.wanfangdata.com.cn/details/detail.do?_type=degree\&id=D01501750

Longo, M. R., \& Lourenco, S. F. (2006). On the nature of near space: Effects of tool use and the transition to far space. Neuropsychologia, 44(6), 977-981. https://doi.org/10.1016/j.neuropsychologia.2005.09.003

Lv, S. X., \& Jiang, L. S. (1985). Modern Chinese demonstratives. Shanghai: Xuelin Press.

Lyons, J. (1977). Deixis, space and time. Semantics, 2, 636-724. https://doi.org/10.1017/CBO9780511620614.008

Morford, M., \& Goldin-Meadow, S. (1992). Comprehension and production of gesture in combination with speech in one-word speakers. Journal of Child Language, 19(3), 559-580. https://doi.org/10.1017/S0305000900011569

Peeters, D., \& Özyürek, A. (2016). This and that revisited: a social and multimodal approach to spatial demonstratives. Front. Psychol., 7, 222. https://doi.org/10.3389/fpsyg.2016.00222

Rocca, R., \& Wallentin, M. (2020). Demonstrative reference and semantic space: A 
large-scale demonstrative choice task study. Front. Psychol., 11, 629. https://doi.org/10.3389/fpsyg.2020.00629

Rocca, R., Tylén, K., \& Wallentin, M. (2019a). This shoe, that tiger: semantic properties reflecting manual affordances of the referent modulate demonstrative use. PLoS One, 14(1), e0210333. https://doi.org/10.1371/journal.pone.0210333

Rocca, R., Wallentin, M., Vesper, C., \& Tylén, K. (2019b). This is for you: social modulations of proximal vs. distal space in collaborative interaction. Sci. Rep., 9, 14967. https://doi.org/10.1038/s41598-019-51134-8

Tanz, C. (1980). Studies in the acquisition of deictic terms. Cambridge: Cambridge University Press.

Tao, H. (1999). The grammar of demonstratives in Mandarin conversational discourse: A case study. Journal of Chinese Linguistics, 27(1), 69-103.

Wang, L. (1985). Theory of Chinese grammar. Beijing: Zhonghua Book Company.

Webb, P. A., \& Abrahamson, A. A. (1976). Stages of egocentrism in children's use of 'this' and 'that': A different point of view. Journal of Child Language, 3(3), 349-367. https://doi.org/10.1017/S0305000900007236

Xu, M. F. (2001). A review of "zhe" and "na" studies. Chinese Language Learning, 5, 47-54.

Xu, X. P., \& Zhou, R. (2011). The influence of pointing distance and pointing mode on the choice of spatial demonstratives. Modern Foreign Languages, 32(4), 408-414.

Yule, G. (1996). Pragmatics. Oxford: Oxford University Press.

Zhu, D. X. (1982). Grammar handouts. Beijing: The Commercial Press.

Zhu, M. S., Cao, J., \& Zhang, R. J. (1986). Children's understanding of demonstratives. Psychological Science, 3, 3-8.

\section{Notes}

Note 1. Though from the aspect of spatial distance, "zhe" as a proximal deixis can be considered as the counterpart of "this" in English, while "na" the counterpart of "that", there, however, exist various differences in usage of intra-discourse reference or guiding clauses. Therefore, this article will use the expression of "zhe" and "na", instead of "this" and "that". It is the same case with "zheli" and "here", "nali" and "there".

Note 2. Colors were covered in experiment on children to facilitate their use of spatial demonstratives.

\section{Copyrights}

Copyright for this article is retained by the author(s), with first publication rights granted to the journal.

This is an open-access article distributed under the terms and conditions of the Creative Commons Attribution license (http://creativecommons.org/licenses/by/4.0/) 